\title{
A Proposed Perspective for Developing Suggested Administrative Rules to Activate Competitive Advantage Indicators in Jordanian Education Directorates \\ Mohammad Hasan Hamadat
}

Associate Professor of Educational Management in the Educational

Sciences Department at Ajloun University College, Al-Balqa

Applied University, Jordan

\begin{abstract}
The current study aimed at developing proposed administrative rules to activate the indicators of competitive advantage in the Jordanian education directorates. The study community comprised (312) educational leaders in these directorates for the first semester of the academic year (2020/2021). The developed study instrument was distributed to an intended study sample of (290) educational leaders. After extracting the validity and reliability coefficients, the results showed that the importance of the indicators of competitive advantage in the Jordanian education directorates. They presented a (high) degree of importance following the educational leaders' estimates in these directorates in four main dimensions as indicating signs of competitive advantage in those education directorates. Based on the study results, administrative rules were drawn up according to the importance of (30) indicators of competitive advantage in the education directorates. These indicators were divided into (4) main dimensions. The researcher recommends including administrative rules in educational institutions and encouraging educational leaders and those in charge of educational and training programs to adhere to them.
\end{abstract}

Keywords: Education Directorates, Indicators of Competitive Advantage, Jordan, Perspective 
A Proposed Perspective for Developing Suggested Administrative Rules to Activate Competitive Advantage Indicators in Jordanian Education Directorates

\section{A Proposed Perspective for Developing Suggested Administrative Rules to Activate Competitive Advantage Indicators in Jordanian Education Directorates \\ Mohammad Hasan Hamadat}

Associate Professor of Educational Management in the Educational Sciences Department at Ajloun University College, Al-Balqa

\section{Introduction}

Applied University, Jordan

The different educational institutions are competing with each other to achieve and maintain a competitive advantage among their human competencies. Creating administrative rules for the competitive advantage activation is regarded as one of the institutions' strengths of distinction and leadership.

And due to the increasing number of public and private schools, their curricula may not consistently fit with the students' needs in different regions and with the labor market. This can be notified by the fact that many students headed to the labor market after the tenth grade or after the end of secondary school. Therefore, each education directorate, as well as every school, is concerned with marketing itself, competing with others, and having the priority of taking the lead in achieving the prestigious quality of its outputs. This requires excellence in its services to ensure the satisfaction of its customers (Al Khawaldeh, 2018).

Hence, investing in and excelling in education has become one of the modern trends. The mission, in educational institutions, is to achieve sustainability at the level of inputs and processes to reach outputs consistent with the requirements of the competitive labor market. Accordingly, this study came to find out the reality of the competitiveness requirements that characterize educational institutions in the dimensions of learning, education, and research. Also, it highlighted the various programs that they include or 
present to society, their objectives, and the mechanism through which they lead to institutional excellence.

\section{Competitive Advantage in Educational Institutions}

The competitive advantage can be defined as "The ability of the educational institution to provide high-quality educational and research service. it is positively reflected on the level of its graduates of students as well as teachers therein, giving them competitive capabilities and advantages in the labor market at its various levels. Meanwhile, it reflects the community's confidence in it, cooperation with it, and the increase in students' demand to join it" (Ibrahim, 2009, 24).

Al- Khawaldeh (2018) defined the competitive advantage as a skill, technology, or distinct resource that allows the organization to perform its business in a manner that is difficult for its competitors to imitate, by practicing activities at the lowest level of cost.

Also, Hassan (2017) defined it as the company's ability to formulate and implement strategies that make it in a better position in relation to other companies operating in the same activity.

Ranjith (2016) defined it as a strategy based on developing the company's business model to push the wheel of growth and development. It provides the company with the opportunity to produce services, goods, and benefits to customers to surpass its competitive counterparts in the market. It achieves more profits for the company, and improves its reputation in market.

Besides, Ejrami (2016) defined it as a policy and management to improve performance, manage, and organize the organizational structure in the company. It is reflected on the quality of services provided so that it excels over its counterparts, increasing the market share of the company, maximizing its profits.

In Jordan, all local attempts to improve quality in educational institutions focused on seminars, and conferences. Also, they relied on the formation of committees to define indicators and set standards for measuring quality in these institutions. And as a result of the lack of a specific indicator describing the complex educational system, it was necessary to find many quantitative and

Egyptian Journal of Educational Sciences (17) Issue 1 (Part One) 2021 
A Proposed Perspective for Developing Suggested Administrative Rules to Activate Competitive Advantage Indicators in Jordanian Education Directorates

qualitative indicators. These indicators' success requires criteria including the organizational and school structure, curricula, methods, and aids. (Qubtan, 2010).

The competitive advantage is referred to as a group of characteristics that make the organization excel and unique. It enables the organization to retain it for a relatively long period, due to the difficulty of simulating it. Besides, the competitive advantage achieves its benefit, enabling it to outperform competitors with its distinct outputs (Al- Sukkar, 2013).

The competitive advantage derives its importance from being the most important requirement to be provided in the business sector during the next stage in preparation for a later one. The competitive advantage is achieved if the product differs from the others, using a differentiation strategy (Jennifer, 2015).

The objectives that the educational institution seeks to achieve by generating a competitive advantage are:

-Entering a new competitive dimension, or dealing with a new type of customer.

Forming a new future perspective for the objectives of the institution.-

- Forming advisory councils for the institution of local and international competencies to participate in shaping the ministry's future And directorates at the global competitive level.

-Determining the skills required from the institution's outputs for the labor market locally and regionally.

- Creating cooperation between educational institutions and educational bodies, internally and externally (Mowery, 2012).

\section{Sources of the competitive advantage of educational institutions}

The competitive advantage is a way to create a new perspective for the future of the educational institution. Thus, there are two main sources for building a competitive advantage, namely:

1- Strategic thinking is an entrance to building a competitive advantage. And to achieve a competitive advantage, the educational institution must implement one of the following competitive

Egyptian Journal of Educational Sciences (18) Issue 1 (Part One) 2021 
strategies. The strategy of leadership in costs to reduce costs, the strategy of excellence, whether in the technical dimension or in providing the product or in marketing and services. As well, the concentration strategy to get to better sites.

2- Resources are the basis for building a competitive advantage. And from these resources, there are quantitative resources that include primary inputs, production equipment, and financial resources. Qualitative resources are other resources to include quality, knowledge (information), technology, and competencies (Kufaine, 2014).

Thus, the creative competition between educational and noneducational institutions has become one of the most prominent features of the twenty-first century. The educational institutions have no choice but to keep pace with the trends and follow the current global developments. It is because educational institutions cannot avoid the effects of globalization and its various repercussions. If the educational institution does not adopt a systematic strategy, it will be far behind and not find correct solutions to its multiple problems and challenges (Kasasbeh, 2014).

There is a set of specifications and classifications that achieve precedence, distinction, and competition for educational institutions, including:

--Exchange of experiences between educational leaders in the center and the dimension in various educational and service dimensions.

-Providing the regional and international character of the academic and training curricula and programs, and educational work with a global perspective.

-Encouraging the preparation and publication of scientific research on the problems faced by the Jordanian Ministry of Education and its directorates.

-Supporting local, regional, and international initiatives in new projects.

-Holding joint seminars, workshops, and conferences, to exchange experiences locally, regionally, and internationally.

Egyptian Journal of Educational Sciences (19) Issue 1 (Part One) 2021 
A Proposed Perspective for Developing Suggested Administrative Rules to Activate Competitive Advantage Indicators in Jordanian Education Directorates

-Maximizing the benefit of the research produced by universities in the educational dimensions.

-Establishing centers of excellence, bringing together educational directorates and ministries, locally, regionally, and internationally. -Finding marketing opportunities for its educational and cognitive outputs and energies (Essanya, 2015).

Many researchers have tackled the topic of competitive advantage in educational and educational institutions. Ghani and Bin Said (2019) conducted a study to identify the effect of administrative creativity in achieving competitive advantage. This study was from the viewpoints of a sample of professors and administrative staff at the Faculty of Literature and Languages, the University of Adrar, as a model. The study used the descriptive and analytical approach. The study population consisted of all faculty members and administrators at the Faculty of Arts, University of Adrar. The researchers used the questionnaire as an instrument to collect data from the study sample. It was distributed to (86) members of the professors and administrators. The results of the study showed that the effect of administrative creativity in achieving competitive advantage at the University of Adrar was average.

Likewise, the study of Al-Ayasrah and Tanash (2017) attempted to identify the reality of the competitive advantage in Jordanian public universities in light of contemporary administrative trends. The study used a questionnaire consisting of (77) items. The study sample consisted of (304) faculty members. The study adopted the descriptive survey approach in collecting data. The study results showed that the degree of estimation of the reality of the competitive advantage in the Jordanian public universities from the study sample members' viewpoints was average. Also, there were no statistically significant differences due to the nature of work variable in all fields. 
The study of (Wangari, 2015) aimed to identify the effect of employing competition strategies on the performance of mid-level colleges in the Takeda district of Kenya. The study sample comprised (92) senior managers and (200) managers in (36) colleges. The researcher used the questionnaire as the study instrument to collect data. The results showed that the dimension of marketing strategies got the highest percentage $(56.3 \%)$. The cooperation dimension got $(26.7 \%)$ and came in the last place. There is a positive relationship between competitive strategies and the performance of middle-level colleges in the district of Takeda. The study of Ahmed and Saeed (2015) aimed to develop a proposed perspective to achieve a competitive advantage in the Faculties of Education in Al-Wadi. Also, it acknowledged the reality of the competitive advantage in the Faculties of Education in the New AlWadi. They used the descriptive approach. The study instrument was applied to a sample comprising (30) members of the faculty at the College of Education in the New Al-Wadi. The results indicated that the proposed perspective is based on the following principles. Developing admission systems that achieve justice and democracy; responding to development needs, taking into account the college's absorptive capacity; developing study plans and programs. Also, it focused on providing students with self-learning skills, as well as imparting language and computer skills. It indicated developing the teaching and administrative staff and all human resources and raising the level of qualification and competence. It insisted on developing scientific research, publishing systems, and graduate studies systems, and activating the role of the private sector in supporting scientific research. The results showed that the main obstacles to competitive advantage in the College of Education in the New Al-Wadi are the lack of compatibility between the plans, programs, and outputs being followed and the needs of the labor market. And the current courses do not encourage the preparation of the researching student and do not market the scientific material. The study of Bisaria (2013 aimed to identify the reasons for achieving competitive advantage in private universities and

Egyptian Journal of Educational Sciences (21) Issue 1 (Part One) 2021 
A Proposed Perspective for Developing Suggested Administrative Rules to Activate Competitive Advantage Indicators in Jordanian Education Directorates

colleges. Also, it attempted to uncover the types of competitive advantage in the education sector, which is one of the mere dimensions. It showed the importance of creating value as a competitive advantage for universities and private colleges. The study also aimed to identify the principles of Knowledge management in competitive advantage. The study community comprised all teachers and administrators in private universities and colleges in Lucknow and Ultra Pradesh region in India. The study sample reached (50) administrative teachers who were chosen randomly. The information was obtained from the use of instruments, the questionnaire, the observation, and the interview, to achieve the purposes of the study. The results showed that to reach the competitive advantage of private universities and colleges, the following suggestions must be taken according to the study sample members' responses. Quality should be taken into consideration. Paying attention that the number of students in universities has a major role in achieving the advantage. The university administration should create a link with the industrial and financial sectors, develop knowledge, and conduct a strategic analysis (SWOT) analysis for competitiveness.

The study of (Essanya, 2015) aimed to investigate the competitiveness strategies of the Nairobi Aviation College. Essanya used the study-case method to obtain qualitative and quantitative data for the study. Data were collected from secondary sources such as newspapers, books, magazines, and research papers on the subject of the study via websites. As for the primary sources, they were obtained from the study sample respondents through applying a questionnaire. Essanya conducted interviews with (5) individuals, the director of the college, the director of human resources, the financial director, the marketing director, the director of registration. The study indicated that Nairobi College adopted all competitive strategies Including cost management, service differentiation, expansion and marketing, and investment in the college's technological infrastructure. The strategies adopted had the effect of

Egyptian Journal of Educational Sciences (22) Issue 1 (Part One) 2021 
opening new branches in the region for the college, introducing a range of modern courses, and making facilities for students to increasingly encourage students for registration.

\section{Previous Studies Commentary}

Reviewing the educational previous literature, there is a plentitude of studies related to measuring capabilities, competitive indicators, and the requirements of competitive advantage in different educational institutions. This is due to the importance of the education sector for creating competitive advantages to make it attract students from different regions. The current study differed from previous ones in the sense it dealt with developing proposed administrative rules to activate the indicators of competitive advantage in Jordanian education directorates.

\section{The study Question}

All educational and non-educational institutions seek to survive and grow in the market. They need to work to provide competitive advantages in their institutions and branches to achieve their objectives and ensure their continuity. The Jordanian Ministry of Education, represented in its various directorates, is striving seriously to face some challenges. These challenges include financial, competitiveness, pressures, and requirements of the diverse, and changing and developing knowledge market. Also, the nature of the unique services provided by educational institutions is another challenge facing the Ministry of Education. It is because they need to work according to foundations relatively different from what is available for other profit organizations.

Thus, the Jordanian Ministry of Education and its various directorates began to adopt indicators of competitive advantage in its institutions in learning and education. These indicators are to improve the educational process and the outputs of the system. Besides, they are to achieve excellence without increasing costs to a level that negatively affects the efficiency and effectiveness of the institution. Therefore, this study pinpointed the following questions:

Egyptian Journal of Educational Sciences (23) Issue 1 (Part One) 2021 
A Proposed Perspective for Developing Suggested Administrative Rules to Activate Competitive Advantage Indicators in Jordanian Education Directorates

1-What are the proposed administrative rules for activating the competitive- advantage indicators in the Jordanian educational directorates?

2-What are the basic rules upon which the competitive advantage in the Jordanian education directorates is built?

3-What are the appropriate administrative rules for indicators of competitive advantage in the Jordanian educational directorates?

\section{Study Objectives}

The current study aims to suggest proposed administrative rules to activate the indicators of competitive advantage by:

- Identifying the indicators of competitive advantage adopted in these directorates or which educational records deem valid for accreditation.

-Determining the basic rules upon which the competitive advantage is built in preparation for their adoption in these directorates.

-Finding the appropriate administrative rules to activate the indicators of competitive advantage in the Jordanian educational directorates.

\section{Study Significance}

The significance of the study stems from the importance of the topic it tackles, what are the proposed administrative rules to activate the competitive -advantage indicators in Jordanian education directorates?

Besides, the significance of the study is derived from the benefits extracted from the results of this study. They will avail different educational institutions by using these rules and activating them to enable their institutions to gain a competitive advantage. Also, they will avail educational leaders as the rules reflecting indicators of competitive advantage that must be available in every competitive institution. Students and parents can get benefit from these rules since the student and his parents can determine what these institutions have of competitive- advantage indicators to be attracted by.

Egyptian Journal of Educational Sciences (24) Issue 1 (Part One) 2021 


\section{Study Methodology}

This study used the developmental survey method which is the most appropriate approach for this type of research.

\section{Study Community and Sample}

The Study Community: It comprised (290) educational leaders, following the statistics of the following education directorates. These directorates include Ajloun, Jerash, Qasbat Irbid, Bani Obaid, Bani Kenana, Ramtha, Al Mazar Al Shamali, Northern Jordan Valley, Al Koura, and Al Wasatia for the academic year 2020/2021. Study Sample: The study sample comprised (290) educational leaders.

\section{Table (1)}

Distribution of the study community following the directorate

\begin{tabular}{|l|l|l|}
\hline Directorate & Number & Percentage \\
\hline Ajloun & 32 & $11 \%$ \\
\hline Jerash & 30 & $10 \%$ \\
\hline Qasbat Irbid & 40 & $14 \%$ \\
\hline Bani Obaid & 27 & $9 \%$ \\
\hline Bani Kenana & 28 & $10 \%$ \\
\hline Ramtha & 30 & $10 \%$ \\
\hline Al Mazar Al Shamali & 27 & $9 \%$ \\
\hline The Northern valleys & 25 & $9 \%$ \\
\hline The Koura & 26 & $9 \%$ \\
\hline Al Wasatia & 25 & $9 \%$ \\
\hline Total & & $\mathbf{1 0 0 \%}$ \\
\hline
\end{tabular}

\section{Study instrument}

The study instrument was developed by relying on previous theoretical literature related to the topic. And to achieve the objectives of the current study, a questionnaire instrument was used to measure the competitive- advantage indicators as seen by educational leaders in the education directorates. The answer ladder was built according to the Fifth-Likert Scale. The answer ladder came as follows, "Strongly Agree" got (5 degrees), "Agree" had (4 
A Proposed Perspective for Developing Suggested Administrative Rules to Activate Competitive Advantage Indicators in Jordanian Education Directorates

degrees). "Averagely Agree" got ( 3 degrees), "Slightly Agree" got (2 degrees), and "very little Agree" had (1 degree). It was used to measure the importance of competitive- advantage indicators in education directorates. The instrument comprised (30) items, measuring the competitive- advantage indicators from the viewpoint of educational leaders, distributed on the following dimensions. The first dimension is "material resources" and got (9) Items. The second dimension is "human resources" and got (6) Items. The third dimension is "the size of the institution" and had (8) Items. The final dimension is "infrastructure" and had (6) Items.

\section{Study Instrument Validity}

Content Validity: The content validity of the study instrument was verified by presenting it to (15) referees who are specialists in educational administration, measurement, and evaluation in Jordanian universities. The researcher asked them to evaluate the degree of relevance of the items of the questionnaire to what they were designed to measure, their suitability to the dimension to which they belong, the degree of clarity of the item, and to suggest appropriate modifications. The items, that were positively evaluated and obtained a score of (80\%) and more, were taken into account.

\section{The Study Instrument Reliability}

The researcher used two methods to verify the reliability of the study instrument: The first method is "test-retest". The researcher applied the instrument to an exploratory sample comprising (15) educational leaders from outside the study sample with a two-week interval between the two application times. The reliability factor was calculated using the Pearson Correlation Coefficient. The Pearson Correlation- Coefficient values were $(0.88,0.85,0.890$, 0.87 , and 0.83 ), respectively, for the study dimensions. The other method is to calculate the degrees of reliability of each of the dimensions of the study and its axes. Table (2) shows the values of Cronbach Alpha for the internal consistency of the study 
Mohammad Hasan Hamadat

dimensions. The values ranged from (0.70) to (0.90) which are high values of reliability.

Table (2)

Pearson Correlation Coefficient and Cronbach Alpha internal consistency values for the study dimensions

\begin{tabular}{|l|l|l|l|}
\hline No. & Study Dimensions & $\begin{array}{l}\text { Pearson } \\
\text { Correlation- } \\
\text { Coefficient }\end{array}$ & $\begin{array}{l}\text { Cronbach Alpha } \\
\text { Coefficient }\end{array}$ \\
\hline $\mathbf{1}$ & $\begin{array}{l}\text { The size and location of the } \\
\text { institution }\end{array}$ & $\mathbf{0 . 8 9}$ & $\mathbf{0 . 7 5}$ \\
\hline $\mathbf{2}$ & Material Resources & $\mathbf{0 . 8 5}$ & $\mathbf{0 . 8 0}$ \\
\hline $\mathbf{3}$ & Human Resources & $\mathbf{0 . 8 8}$ & $\mathbf{0 . 9 0}$ \\
\hline $\mathbf{4}$ & Infrastructure & $\mathbf{0 . 8 7}$ & $\mathbf{0 . 7 0}$ \\
\hline Total Degree & $\mathbf{0 . 8 3}$ & $\mathbf{0 . 8 0}$ \\
\hline
\end{tabular}

Study Results

The study's first question is "What is the importance of indicators of competitive advantage in educational institutions as perceived by educational leaders in Jordanian education directorates?"

To answer the first question, arithmetic averages and standard deviations were extracted to show the importance of the requirements for building a competitive advantage in educational institutions. They were extracted from the educational leaders' points of view in Jordanian education directorates in general and for each domain of the study instrument in specific.

Table (3)

Arithmetic averages and standard deviations of the importance of the requirements for building a competitive advantage in educational institutions. They were extracted from the educational leaders' points of view in the Jordanian education directorates as being arranged in descending order

\begin{tabular}{|r|r|r|r|r|r|}
\hline Number & Rank & The Dimension & $\begin{array}{r}\text { Arithmetic } \\
\text { Averages }\end{array}$ & $\begin{array}{r}\text { Standard } \\
\text { Deviations }\end{array}$ & $\begin{array}{r}\text { Degree } \\
\text { Rating }\end{array}$ \\
\hline 2 & 1 & Human Resources & 4.25 & $\mathbf{0 . 7 5}$ & High \\
\hline 3 & 2 & Finance Resource & 4.20 & $\mathbf{0 . 7 2}$ & High \\
\hline 1 & 3 & Infrastructure & 4.10 & 0.76 & High \\
\hline 4 & 4 & $\begin{array}{r}\text { The size and location } \\
\text { of the institution }\end{array}$ & 4.00 & 0.74 & High \\
\hline \multicolumn{7}{|r|}{ The total degree of administrative rules } & 4.20 & & High \\
\hline
\end{tabular}

Egyptian Journal of Educational Sciences (27) Issue 1 (Part One) 2021 
A Proposed Perspective for Developing Suggested Administrative Rules to Activate Competitive Advantage Indicators in Jordanian Education Directorates

Table (3) shows that the degree of importance of competitiveadvantage indicators in educational institutions as seen by educational leaders in education directorates got a high degree. They had an arithmetic mean (4.20) and a standard deviation (0.75). The dimension of "Human Resources" came first with an arithmetic mean (4.25), a standard deviation (0.75), getting a high degree. The dimension of "Financial Resources" came in second place, getting an arithmetic mean (4.20), a standard deviation (0.72), and a high rating. The dimension of "Infrastructure" came in third place with an arithmetic mean (4.10), a standard deviation (0.76), and with a high rating degree. The dimension of "size and location of the institution" came in the last place with an arithmetic mean (4.00), a standard deviation (0.74), and with a high rating degree.

The second question: What are the basic rules upon which the competitive advantage in Jordanian education directorates is built?

To determine the basic rules upon which the indicators of competitive advantage are based, the following has been done:

A- Conducting a Factor Analysis by using Principle Component Analysis for the items of each of the four dimensions of the competitive- advantage indicators. The Eigenvalues were used for the various factors in the proposed -dimension rules as a whole. And the ratio of variance and cumulative variations of fluorescence was explained by each of those factors. The results showed the presence of a single latent factor. The value of the latent root was more than (1), being a prevalent factor among them. It is indicated by the differences between the value of the first and the second latent roots, and the value of the third and the fourth latent roots. 
Mohammad Hasan Hamadat

Table (4)

The values of the latent root of the various factors for the four indicator dimensions as a whole, the percentage of variance, and the cumulative variance ratio were explained by each factor

\begin{tabular}{|l|l|l|l|}
\hline Factors & $\begin{array}{l}\text { The } \\
\text { Latent } \\
\text { Root }\end{array}$ & $\begin{array}{l}\text { The explained- } \\
\text { Variance Ratio }\end{array}$ & $\begin{array}{l}\text { The cumulative ratio } \\
\text { of explained } \\
\text { variance\% }\end{array}$ \\
\hline 1 & 6.067 & $75.843 \%$ & $75.843 \%$ \\
\hline 2 & 0.459 & $5.731 \%$ & $81.574 \%$ \\
\hline 3 & 0.372 & $4.678 \%$ & $86.252 \%$ \\
\hline 4 & 0.241 & $3.021 \%$ & $92.741 \%$ \\
\hline
\end{tabular}

The results of the factor analysis of the previous four-dimension indicators revealed only one prevailing indicator in each of them. This indicates that each of these indicators measures a dimension to which the indicator was designed to measure.

B-Correlation coefficients between item degree, dimension degree, and scale as a whole one. To verify the validity of the indicator rules, the researcher calculated Pearson Correlation Coefficients among the educational leaders' ratings in the education directorates. The researcher calculated their ratings on the dimensions of the rules and indicators of competitive advantage and ratings on the rules of indicators of the total competitive advantage. 
A Proposed Perspective for Developing Suggested Administrative Rules to Activate Competitive Advantage Indicators in Jordanian Education Directorates

Table (5)

Pearson correlation coefficients between the estimates of educational leaders in education directorates on the dimensions of indicators of competitive advantage in educational institutions

\begin{tabular}{|l|l|l|}
\hline Dimension & The statistics & $\begin{array}{l}\text { Correlation } \\
\text { Coefficient between } \\
\text { the principle and the } \\
\text { overall scale }\end{array}$ \\
\hline $\begin{array}{l}\text { The Size and Location of the } \\
\text { Institution }\end{array}$ & $\begin{array}{l}\text { Correlation } \\
\text { Coefficient Value }\end{array}$ & 0.72 \\
\cline { 2 - 3 } & $\begin{array}{l}\text { Statistical } \\
\text { Significance }\end{array}$ & $* 0.00$ \\
\hline Human Resources & $\begin{array}{l}\text { Correlation } \\
\text { Coefficient Value }\end{array}$ & 0.63 \\
\cline { 2 - 3 } & $\begin{array}{l}\text { Statistical } \\
\text { Significance }\end{array}$ & $* 0.00$ \\
\hline Finance Resource & $\begin{array}{l}\text { Correlation } \\
\text { Coefficient Value }\end{array}$ & 0.76 \\
\cline { 2 - 3 } & $\begin{array}{l}\text { Statistical } \\
\text { Significance }\end{array}$ & $* 0.00$ \\
\hline Infrastructure & $\begin{array}{l}\text { Correlation } \\
\text { Coefficient Value }\end{array}$ & 0.79 \\
\cline { 2 - 3 } & $\begin{array}{l}\text { Statistical } \\
\text { Significance }\end{array}$ & $* 0.00$ \\
\hline
\end{tabular}

* statistically significant at the significance level $(\alpha \leq 0.05)$

There were values of Pearson Correlation Coefficients between the educational leaders' ratings on the dimensions of the competitiveadvantage rules and their ratings on the total-advantage indicating rules. These values ranged from (0.79) to (0.63). All those correlation coefficients are significant at the level of significance $(\alpha \leq 0.05)$.

The third question: What are the appropriate administrative rules for indicators of competitive advantage in educational institutions?

Egyptian Journal of Educational Sciences (30) Issue 1 (Part One) 2021 
To answer this question, administrative rules have been set up to activate the indicators of competitive advantage in educational institutions. The questionnaire comprised(30) indicators distributed to four dimensions as being explained in table (6).

Table (6)

\begin{tabular}{|l|l|l|l|}
\hline Number & Dimension & $\begin{array}{l}\text { Items } \\
\text { Number }\end{array}$ & $\begin{array}{l}\text { Relative } \\
\text { Significance }\end{array}$ \\
\hline 1 & $\begin{array}{l}\text { The Size and Location } \\
\text { of the Institution }\end{array}$ & 7 & $\% 23$ \\
\hline 2 & Finance Resource & 8 & $\% 27$ \\
\hline 3 & Human Resources & 9 & $\% 30$ \\
\hline 4 & Infrastructure & 6 & $\% 20$ \\
\hline \multicolumn{2}{|l|}{ The Rules of Indicators as a whole } & $\mathbf{3 0}$ & $\mathbf{1 0 0 \%}$ \\
\hline
\end{tabular}

The results showed that the dimension of "human resources" ranked first with the (9) items and (30\%) relative significance. The dimension of "financial resources" came in second place with (8) items and (27\%) relative significance. The third place was for the dimension of "size and location of the institution" with (7) items and $(23 \%)$ relative significance. The last place was for the dimension of "infrastructure" with (6) items and (20\%) relative significance. Administrative rules took the following form:

Reviewing the previous literature and the results of the field study, it is possible to develop proposed administrative rules activating the competitive- advantage indicators in the Jordanian education directorates. This can be done by stating the philosophy of the proposed rules, foundations of the proposed rules, objectives of the proposed rules, and proposed rules procedures.

\section{1-Proposed Rules Philosophy}

These rules are based on a philosophy that activating the indicators of competitive advantage for educational institutions depends on a set of requirements, dimensions, strategies, and competitive advantages. 
A Proposed Perspective for Developing Suggested Administrative Rules to Activate Competitive Advantage Indicators in Jordanian Education Directorates

\section{2- The Foundations on which the Proposed Rules Are Based}

The proposed rules are based on a set of foundations to achieve the competitive- advantage indicators in the Jordanian education directorates. These foundations are as follows:

-Developing curricula, textbooks, plans, and training programs while providing educational leaders with various skills.

- Developing educational leaders, and all human resources, in the Jordanian education directorates, upgrading them to the level of efficiency and effectiveness.

-Developing the examination system and the foundations for admission in various school stages, from kindergarten to secondary school. It is to achieve justice between the directorates, o respond to the needs of development, and take into account the absorptive capacity of schools.

-Developing the infrastructure of schools and districts, creating what is commensurate with population growth.

-Paying attention to educational research, encouraging it, and directing it towards existing and expected problems.

\section{3- Objectives of the Proposed Rules}

This study aims to achieve the following:

-Activating the competitive advantage indicators in the Jordanian education directorates.

-Upgrading educational leadership to globally competitive levels.

\section{4- Procedures for Implementing the Proposed Administrative Rules}

To achieve the two previous objectives, the researcher presents the procedures through which these two objectives are achieved as follows:

A- Defining the competitive advantage indicators that should be available in the Jordanian education directorates.

B- Identifying the obstacles that hinder the activation of the competitive advantage in the Jordanian education directorates. 
C- Methods for facing the obstacles that hinder the activation of competitiveness in the Jordanian education directorates.

D- Following-up and evaluation.

Determining the Features of the Competitive Advantage in the Jordanian Directorates of Education

There are some strategic objectives to enhance the competitive position of education directorates in Jordan and achieve them, including:

-Conducting distinctive programs such as training programs for educational leaders on modern methods of teaching, evaluation, psychological and educational counseling, programs of learning difficulties, physical and health disabilities.

-Creating open and distance education programs.

-Sending several distinguished educational leaders to Jordanian universities to obtain academic qualifications such as masters' and doctoral degrees.

- Encouraging some educational leaders to receive state awards.

Some societal challenges require some directorates or schools, due to their location, to confront them and interact with them in the context of their social criticism. And among these challenges are the following:

-Preparing programs to attract investors or donors from the private sector to establish schools to accommodate the increasing numbers of distinguished or handicapped students.

-The contribution of educational leaders in projects of technological and reading literacy among students, teachers, and parents.

-Preparing textbooks and courses that suit the nature of the new society and its development projects.

-Involving principals and teachers in functional committees to select educational leaders. 
A Proposed Perspective for Developing Suggested Administrative Rules to Activate Competitive Advantage Indicators in Jordanian Education Directorates

\section{Identifying the obstacles that hinder the activation of the competitive advantage of educational institutions}

Many difficulties face educational institutions, preventing them from continuing to progress and achieving excellence, namely:

-The lack of consistency between the adopted plans, programs, outputs, and the labor market needs.

-Current and training courses do not encourage educational leaders.

- The presence of a relative deficiency in the educational leaders' capabilities, which imposes on the state the burden of re-training and educating them professionally.

-The presence of a relative deficiency in some educational leaders' applied skills, especially those who did not have the opportunity for practical application during their professional activities.

-Creating education directorates and public schools, especially in densely populated areas.

\section{Conclusion}

This study aimed to develop a proposed perspective to develop proposed administrative rules to activate the indicators of competitive advantage in the Jordanian directorates of education. The researcher believed in the importance of the availability of administrative rules starting from the educational leader in his or her work, to work on activating the indicators of competitive advantage in the educational institution. It is because of the competitive advantage of the importance lies in the survival of the educational institution, its development and excellence among other competing institutions. Especially as we live in an age of competition as a result from the technological and cognitive growth and the speed of communication.

This study has developed a set of administrative rules that can be included in the Jordanian directorates of education to activate the competitive-advantage indicators. Besides, these competitiveadvantage indicators are possibly to be used in other similar educational institutions. 


\section{Overcoming the difficulties that hinder the activation of the} competitive advantage can be through:

-Restructuring plans and programs in educational institutions to suit their outputs and the needs of the labor market.

-Reviewing current courses and training programs to motivate educational leaders while preparing and developing them.

- Overcoming the weakness of educational leaders by encouraging them to enroll in internal and external training courses and linking this to their promotions.

-Providing educational leaders with the opportunity to acquire applied skills by enrolling them in intensive educational workshops and courses.

-Re-surveying the needs of densely populated areas in preparation to supply them with all their educational needs.

\section{Recommendations}

Through the study results, the researcher presents a set of recommendations that will hopefully contribute to the commitment to activate the competitive- advantage indicators in educational institutions:

-Including administrative rules in educational institutions and encouraging educational leaders and those in charge of educational and training programs to adhere to them.

-The Jordanian Ministry of Education adopts administrative rules for activating competitive- advantage indicators. 
A Proposed Perspective for Developing Suggested Administrative Rules to Activate Competitive Advantage Indicators in Jordanian Education Directorates

\section{References}

- Ahmed, Saeed. (2015). A proposed conception to activate the competitive advantage in the College of Education in the New Valley. The Scientific Journal of the College of Education, Volume 31, Issue (3), pp. 648-725.

- Al-Ayasrah, Mahmoud, Tanash, Salama. (2017). The reality of the competitive advantage in Jordanian public universities in light of contemporary administrative trends. The Jordanian Educational Society, The Jordanian Educational Review, Volume (2), Issue (1), pp. 179-212

- Al-Khawaldeh, Muhammad Falah. (2018). Proposed administrative rules to activate indicators of competitive advantage in higher education institutions. Dirasat Journal, Educational Sciences, Volume (45), Issue (4), pp. 134-150.

- $\quad$ AL-Sukkar, A. (2013). The effect of so vial responsibility in achieving competitive advantage. International journal of business and social science, 4(5).

- $\quad$ Bisaria, G.(2013). Achieving competitive advantage by private management colleges or private universities. International Journal of Social Science \& Interdisciplinary Research, 2(93), 90- 150.

Ejrami, M., Salehi, N., Ahmadian, S. (2016). The effect of marketing capabilities on competitive advantage and performance with moderating role of risk management in importation companies. Procedia Economics and Finance, 36, 22-28.

- Essanya, E. (2015). Competitive strategies adopted by Nairobi Aviation College, Kenya. Master of Business Thesis, University of Nairobi.

- Ghani, Zahra, Ben Said Gautieh. (2019). The impact of administrative creativity in achieving competitive advantage: A study from the viewpoint of a sample of professors and administrative staff at the Faculty of

Egyptian Journal of Educational Sciences (36) Issue 1 (Part One) 2021 
Literature and Languages, University of Adrar as a model. (Unpublished Master's Thesis). Algeria: Ahmed Deraya University od Adrar.

- Hassan, Ahmad. (2017). The impact of total quality management practices in achieving competitive advantage: A field study in Jordanian pharmaceutical companies according to the size of the companies. (A Master's Thesis in business administration). Amman: Middle East University.

- Ibrahim, Muhammad. (2009). Competitive projects in Egyptian universities between reality and expectations, research presented to the Second International Conference for the Development of Higher Education (Contemporary Trends in University Performance Development), 1-2 November, Mansoura University.

- Jennifer, S. (2015). Quality Indicators in Higher Education Institution: Implication to global Competitiveness, The Online Journal of Quality in Higher Education, Volume 2, Issue 4,53 - 61.

- $\quad$ Kufaine, N, (2014). Competitive Strategies in Higher Education: Case of Universities In Malawi, The International Journal of Social Sciences and Humanities Invention Volum 1, issue 7. Pp, 490 - 499.

- Kasasbeh, E.(2014). The Impact of business ethics in the competitive advantage in the cellular communications companies operating in Jordan, European Scientific Journal,10(10).

- $\quad$ Mowery, D.(2012). The changing role of universities in the 21st century U.S.R\&D system. The 26th annual AAAS Colloquium on Science and technology policy. Washington D.C., 3-4 May.

- -Qubtan, SH. (2010). Excellence management: the modern philosophy of the success of organizations in the era of globalization and competition, the fourth international forum competition and competitive strategies for institutions in the Arab countries. Faculty of Economics and Facilitation Sciences, Algeria, November $9^{\text {th }}$. 
A Proposed Perspective for Developing Suggested Administrative Rules to Activate Competitive Advantage Indicators in Jordanian Education Directorates

- Ranjith, V. (2016). Business models and competitive advantage. Procedia Economics and Finance, 37, 203-207.

-Wangari, G. (2015). Effects of competitive strategies on the performance of middle-level colleges in Theca sub-county. International Academic Journal of Human Resource and Business Administration, 1 (5), 83- 106. 